\title{
STUDY ON THE INFLUENCE OF CCD DETECTOR TEMPERATURE ON THE PERFORMANCE OF THE SPACE REMOTE SENSING CAMERA
}

\author{
Zhang Xiaohong ${ }^{1, *}$, Wang Xiaoyong ${ }^{1}$, Han Zhixue ${ }^{1}$, Li Chunmei ${ }^{1}$, Lu Pan ${ }^{1}$, Zheng Jun ${ }^{1}$ \\ ${ }^{1}$ Beijing Institute of Space Mechanics \& Electricity, 104 Youyi Road, Beijing 100094, China - zxh442@sina.com
}

Commission VI, WG Vl/4

KEY WORDS: Remote Sensing Camera, Charge-coupled Device, Temperature, Signal-to-Noise Ratio, Dynamic Range, ISPRS Archives

\begin{abstract}
:
The CCD detector is the core device of the space remote sensing camera. The performance of CCD detector greatly affects the performance of the whole remote sensing camera. The temperature of the CCD detector has a significant influence on its performance. In order to better study this influence relationship, the temperature impact verification of remote sensing camera detector was carried out. The test scheme of dark signal under high temperature environment and the test scheme of radiation calibration under different temperature conditions are developed. And the test verification was completed. Based on the analysis of the experimental data, the quantization relationship of the influence of temperature on the parameters such as dark signal, dark noise, dynamic range, noise and signal-to-noise ratio is obtained. These results have certain reference value for the development of space remote sensing camera.
\end{abstract}

\section{INTRODUCTION}

The CCD detector is the core device of the space remote sensing camera. The performance of CCD detector greatly affects the performance of the whole remote sensing camera. The temperature of the CCD detector has a significant influence on its performance. In order to study the influence of different temperature of CCD detector on CCD performance, a scheme of test verification was developed. According to the test scheme, the temperature impact test of 8192 pixel TDICCD detector was verified. The experimental results are analyzed, and the quantitative relation between the performance of $C C D$ detector (dark signal, dynamic range) and temperature is obtained.

\section{TEMPERATURE VERIFICATION TEST SCHEME OF CCD DETECTOR}

The detector used is a linear array type TDICCD, the pixel size is 7um $x 7$ um, the pixel number is 8192 , and the maximum TDI stages is 96 . In the experiment, the horizontal transfer frequency of TDICCD was $16.67 \mathrm{MHz}$, the integral time was $1.05 \mathrm{~ms}$, and the quantized number was 14 bits.

Test the dark signals of TDICCD at different temperatures in the atmospheric heat cycle box. TDICCD and corresponding focal plane circuit and signal processing circuit are all placed in the normal pressure heat circulation box. The power supply, thermal control equipment and image acquisition equipment are placed outside the heat circulation box. During the test, the inside of the thermal circulation box is completely black (no light). The connection relationship of each device is shown in figure 1.

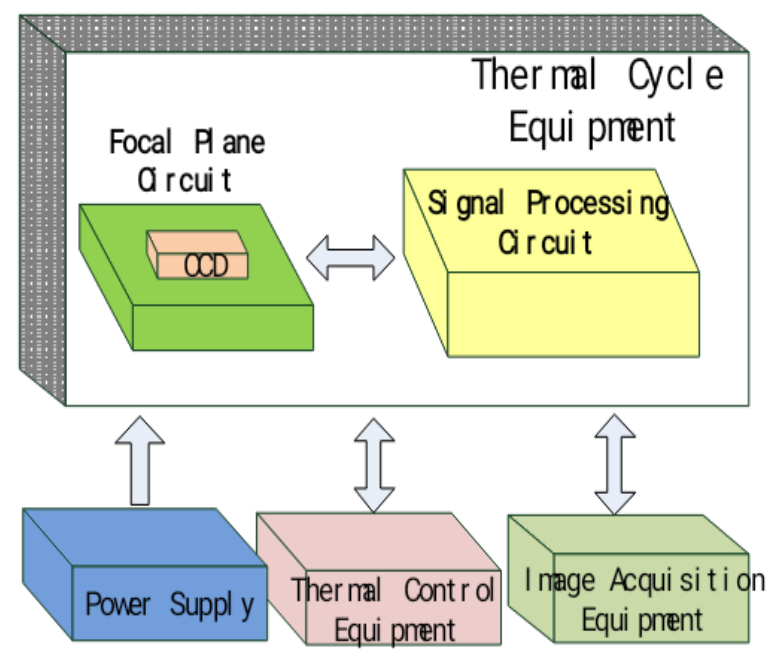

Figure 1. Test equipment connection.

Test temperature scope set to $30{ }^{\circ} \mathrm{C}$ to $15{ }^{\circ} \mathrm{C} \sim+$. Temperature control precision is $+/-1{ }^{\circ} \mathrm{C}$. Every $5^{\circ} \mathrm{C}$ set a test point. As small as possible. The heat preservation time of each temperature point is 15 minutes. The temperature of the CCD device is to be measured and the temperature is basically stable. FIG. 2 is the setting of test temperature and thermal insulation time. Figure 3 is the TDICCD, focal plane circuit and signal processing circuit participating in the experiment. 


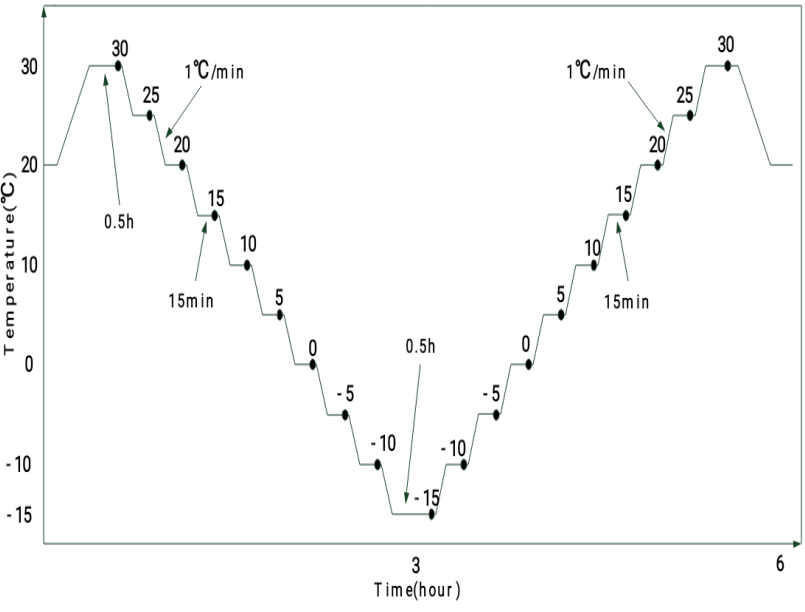

Figure2. The setting of test temperature and thermal insulation time

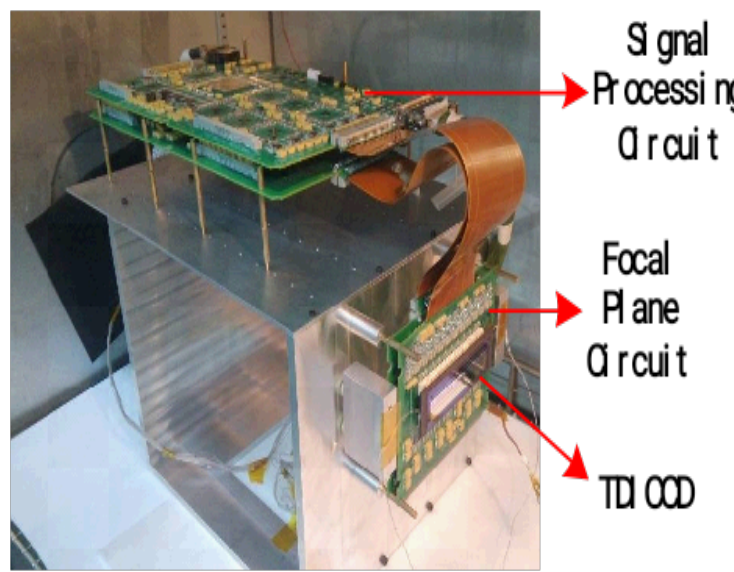

Figure 3. TDICCD, focal plane circuit and signal processing circuit participating in the experiment

The experiment is conducted according to the following steps:

(1) device connection, self-check, close the light source in the oven, block the CCD, and make the CCD completely black.

(2) by $1{ }^{\circ} \mathrm{C} / \mathrm{min}$ heating rate up to $30^{\circ} \mathrm{C}$, heat preservation after $0.5 \mathrm{~h}$, electric equipment, collection and image.

(3) by $1{ }^{\circ} \mathrm{C} / \mathrm{min}$ cooling rate of cooling to $25^{\circ} \mathrm{C}$. After $15 \mathrm{~min}$ heat preservation, the equipment is energized and the image is collected.

(4) by $1{ }^{\circ} \mathrm{C} / \mathrm{min}$ cooling rate of cooling to $20^{\circ} \mathrm{C}$. After $15 \mathrm{~min}$ heat preservation, the equipment is energized and the image is collected.

(5) by $1{ }^{\circ} \mathrm{C} / \mathrm{min}$ cooling rate and cooling, 15 min after each temperature point insulation, electric equipment, collection and image.

(6) by $1{ }^{\circ} \mathrm{C} / \mathrm{min}$ cooling rate of cooling to $15^{\circ} \mathrm{C}$. After $0.5 \mathrm{~h}$ insulation, the equipment is energized and the image is collected.

(7) by $1{ }^{\circ} \mathrm{C} / \mathrm{min}$ heating rate up to $10^{\circ} \mathrm{C}$. After $15 \mathrm{~min}$ heat preservation, the equipment is energized and the image is collected.

According to the $1^{\circ} \mathrm{C} / \mathrm{min}(8)$ heating rate, temperature of each point heat preservation for $15 \mathrm{~min}$, electric equipment, after collecting images.

(9) by $1{ }^{\circ} \mathrm{C} / \mathrm{min}$ heating rate up to $30^{\circ} \mathrm{C}$. After $0.5 \mathrm{~h}$ insulation, the equipment is energized and the image is collected.

(10) by $1{ }^{\circ} \mathrm{C} / \mathrm{min}$ cooling rate and cooling to room temperature, the end of the test.

Each temperature point continuously collects 1024 lines of images, that is, each temperature point can obtain an image of 8192 (column) x 1024 (line).

\section{TEMPERATURE VERIFICATION TEST RESULTS OF CCD DETECTOR}

The mean value of the dark signal and the mean square root of the TDICCD at different temperatures can be obtained by calculating the image collected at each temperature point. Table 1 shows the calculation results of dark signals at different temperatures of TDICCD. Table 2 shows the calculation results of dynamic range of the detector at different temperatures.

\begin{tabular}{|c|c|c|c|}
\hline \multirow{2}{*}{$\begin{array}{l}\text { Set } \\
\text { temperature } \\
{ }^{\circ} \mathrm{C}\end{array}$} & \multirow{2}{*}{$\begin{array}{l}\text { The actual } \\
\text { temperature } \\
\text { measured } \\
{ }^{\circ} \mathrm{C}\end{array}$} & \multicolumn{2}{|c|}{ Dark signal value } \\
\hline & & $\begin{array}{l}\text { The } \\
\text { average } \\
\text { value }\end{array}$ & $\begin{array}{l}\text { Root } \\
\text { mean } \\
\text { square } \\
\text { value }\end{array}$ \\
\hline 30 & 30.0 & 571.19 & 13.457 \\
\hline 25 & 25.5 & 429.78 & 12.197 \\
\hline 20 & 20.8 & 330.31 & 11.163 \\
\hline 15 & 15.9 & 263.32 & 10.349 \\
\hline 10 & 10.9 & 223.06 & 9.772 \\
\hline 5 & 5.8 & 199.20 & 9.348 \\
\hline 0 & 1.0 & 184.61 & 9.058 \\
\hline-5 & -4.1 & 176.51 & 8.875 \\
\hline-10 & -9.0 & 171.67 & 8.731 \\
\hline-15 & -14.1 & 168.40 & 8.623 \\
\hline-10 & -9.2 & 172.98 & 8.735 \\
\hline-5 & -4.3 & 177.92 & 8.880 \\
\hline 0 & 0.4 & 185.50 & 9.074 \\
\hline 5 & 5.5 & 198.36 & 9.342 \\
\hline 10 & 10.4 & 220.68 & 9.733 \\
\hline 15 & 15.2 & 257.83 & 10.294 \\
\hline 20 & 20.1 & 317.91 & 11.046 \\
\hline 25 & 25.0 & 413.84 & 12.085 \\
\hline 30 & 30.3 & 559.65 & 13.421 \\
\hline
\end{tabular}

Table 1. The calculation results of dark signals at different temperatures of TDICCD

\begin{tabular}{|l|l|c|}
\hline $\begin{array}{l}\text { Set } \\
\text { temperature } \\
{ }^{\circ} \mathrm{C}\end{array}$ & $\begin{array}{l}\text { The actual } \\
\text { temperature } \\
\text { measured } \\
{ }^{\circ} \mathrm{C}\end{array}$ & Dynamic range \\
\hline 30 & 30.0 & $1175.06: 1$ \\
\hline 25 & 25.5 & $1308.04: 1$ \\
\hline 20 & 20.8 & $1438.12: 1$ \\
\hline 15 & 15.9 & $1557.70: 1$ \\
\hline 10 & 10.9 & $1653.80: 1$ \\
\hline 5 & 5.8 & $1731.36: 1$ \\
\hline 0 & 1.0 & $1788.41: 1$ \\
\hline-5 & -4.1 & $1826.20: 1$ \\
\hline-10 & -9.0 & $1856.87: 1$ \\
\hline-15 & -14.1 & $1880.51: 1$ \\
\hline-10 & -9.2 & $1855.87: 1$ \\
\hline-5 & -4.3 & $1825.01: 1$ \\
\hline 0 & 0.4 & $1785.16: 1$ \\
\hline
\end{tabular}




\begin{tabular}{|l|l|l|}
\hline 5 & 5.5 & $1732.57: 1$ \\
\hline 10 & 10.4 & $1660.67: 1$ \\
\hline 15 & 15.2 & $1566.56: 1$ \\
\hline 20 & 20.1 & $1454.47: 1$ \\
\hline 25 & 25.0 & $1321.49: 1$ \\
\hline 30 & 30.3 & $1179.07: 1$ \\
\hline
\end{tabular}

Table 2. The calculation results of dynamic range of the detector at different temperatures

After analyzing the experimental data, the influence of temperature on the dark signal and dynamic range of TDICCD is obtained. Figure 4 is the quantitative relationship between temperature and the mean value of dark signals. FIG. 5 is the quantitative relationship of the influence of temperature on the mean square root of dark signal (dark noise). Figure 6 is the quantitative relationship between temperature and dynamic range of the detector.



Figure 4. the quantitative relationship between temperature and the mean value of dark signals

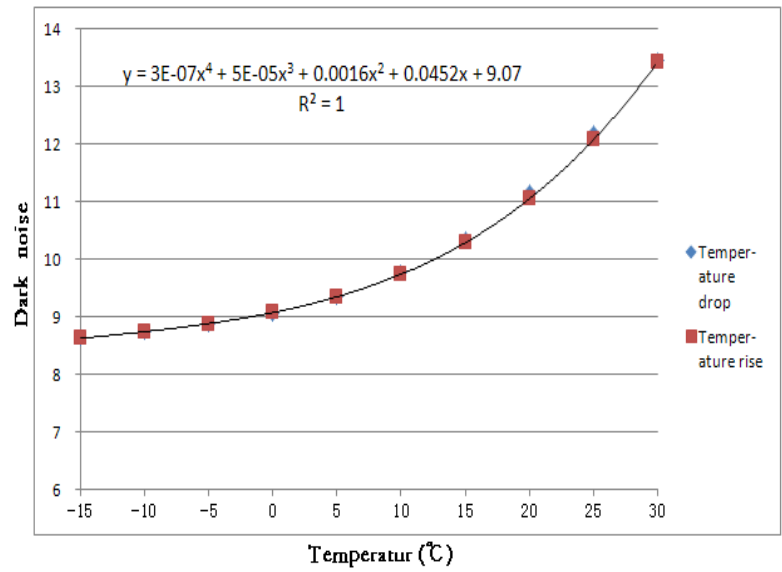

Figure 5. the quantitative relationship of the influence of temperature on the mean square root of dark signal (dark noise)

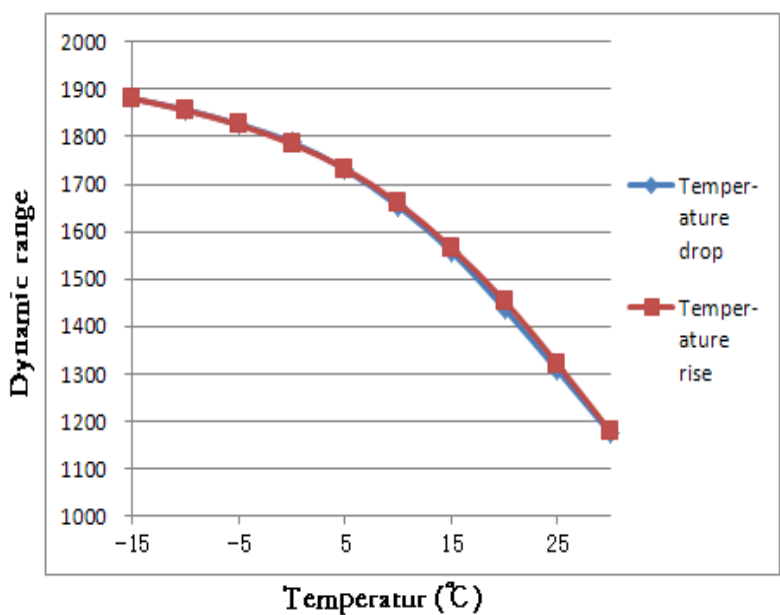

Figure 6 . the quantitative relationship between temperature and dynamic range of the detector

\section{CONCLUSION}

The influence of temperature on TDICCD dark signal and dynamic range is obtained by analyzing the experimental results. The following conclusions can be obtained :(1) the lower the control temperature of CCD, the lower the dark signal level of CCD, and the lower the dark signal noise; (2) using temperature control technology can reduce the dark signal of CCD, especially the dark signal noise, which can improve the dynamic range of the camera and improve the imaging capability of the camera with low irradiance.

\section{REFERENCES}

BOGAART E W,HOEKSTRA W. ,2009,Very low dark current CCD image sensor [J]. IEEE Ttansactions on Electron Devices, 56(11):2462-2467.

JANESICK J R. ,2001,Scientific charge - coupled devices [M]. Bellingham,WA:SPIE Press.

TOM E.,1989,Charge - coupled device pinning technologies [J]. Optical Sensors and Electronic Photography,1071:153-169.

Hashimotodani K, Toneri T, Kitamoto S, 1998. Measurement of quantum efficiency of a charge coupled device [J]. Review of Scientific Instruments, 69(11):3746

Kriss Michael, Parulski Ken, David Lewis, 1989. Critical technologies for still imaging systems [A]. SPIE [C], 157183.

Jim Janesick, Tom Ellion,1995. Sandbox CCDs [A]. SPIE [C], 2415.

\section{Revised March 2018}

